\title{
Analisis Terjemahan Tuturan yang Mengakomodasi Penyimpangan Maksim Kualitas dalam Novel "Me Before You" Karya Jojo Moyes
}

\author{
Ria Aresta \\ Universitas Sebelas Maret, Surakarta, Indonesia \\ Email: aresta.ria1515@gmail.com
}

\begin{tabular}{|c|c|}
\hline Article Info & ABSTRACT \\
\hline Article history: & Translating the implied meaning in the utterances is regarded as one of \\
\hline Submitted Aug 26, 2017 & $\begin{array}{l}\text { the most challenging work the translators may confront. Oneof the } \\
\text { examples is in translating the utterances containing flouting the maxim of }\end{array}$ \\
\hline Revised May 5, 2018 & quality. The speaker may imply something else that isnot represented in \\
\hline Accepted November 5, 2018 & the utterance.Consequently, translators must be able to consider the \\
\hline Published November 21, 2018 & $\begin{array}{l}\text { appropriate translation technique to be applied in order to generate a } \\
\text { qualified outcome. This study aims at (1) identifying the strategies used in }\end{array}$ \\
\hline Keywords: & $\begin{array}{l}\text { flouting the maxim of quality, (2) discovering the translation techniques } \\
\text { that are applied in translating the utterances, (3) investigating how }\end{array}$ \\
\hline Translation & translation techniques may affect translation quallity in terms of its \\
\hline Flouting the maxim of quality & 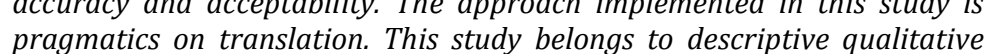 \\
\hline Flouting maxim strategy & research with the embedded case study. The data are all the utterances \\
\hline Translation technique & containing flouting maxim of quality in the source text and its translation. \\
\hline Translation Accuracy & $\begin{array}{l}\text { Content analysis and focus group discussion were applied as the methods } \\
\text { to collect and analyze the data. The result of this research shows that } \\
\text { sarcasm is used the most in flouting maxim of quality, In total, there are } 14 \\
\text { translation techniques applied by the translator. Established equivalent } \\
\text { appears to be the most frequent used technique and it is known to have } \\
\text { positive effect to translation accuracy, while modulation, generalization, } \\
\text { literal translation, reduction, amplification (addition), and discursive } \\
\text { creation have caused strategy shifts which then, contributing to the low } \\
\text { score of translation accuracy. }\end{array}$ \\
\hline
\end{tabular}

Corresponding Author:

Ria Aresta,

Postgraduate Program of Universitas Sebelas Maret, Surakarta, Indonesia

Jl. Ir. Sutami 36 A, Kentingan, Surakarta, Indonesia.

Email: aresta.ria1515@gmail.com

\section{PENDAHULUAN}

Kegiatan penerjemahan telah berlangsung sejak dulu. Penerjemahan mencakup transfer makna dari teks sumber ke dalam teks target (Larson, 1984). Penerjemahan dapat menjadi penghubung dalam proses transfer informasi antara pengguna teks yang berbeda. Penerjemahan berkualitas sangat dibutuhkan untuk menjembatani hubungan dua budaya tersebut. Misalnya saja dalam bidang sastra, sekarang ini telah banyak dijumpai karya penulis dunia yang sudah diterjemahkan ke dalam bahasa Indonesia. Karya yang paling mendominasi adalah dalam bentuk novel, cerpen dan esai. Bagi 
penikmat karya sastra barat, hasil karya terjemahan akan sangat membantu ketika dibaca dalam bahasa yang lebih familiar.

Dalam menerjemahkan novel, penerjemah dihadapkan dengan banyak percakapan yang terjadi antar tokoh dalam cerita. Percakapan tersebut sering kali mengandung maksud-maksud tertentu yang berbeda dengan struktur bahasa yang digunakan. Salah satunya adalah implikatur yang muncul sebagai akibat penyimpangan maksim prinsip kerja sama. Dalam hal ini, penerjemah dituntut agar dapat memutuskan dengan cara apa ia akan menerjemahkan teks tersebut, apakah implikatur akan diterjemahkan menjadi implikatur atau makna implisit pada implikatur akan diterjemahkan secara lebih eksplisit (Sumardiono, 2010). Berikut ini adalah salah satu contoh penyimpangan maksim kualitas dalam bahasa sumber serta terjemahannya:

\section{Bahasa sumber}

Katreena : Thanks Josh, you are very helpful!

\section{Bahasa sasaran}

Katreena : Oh, terimakasih Josh, kau sangat membantu!

Tuturan tersebut berlangsung ketika Katreena sedang membereskan barangbarangnya karena ia baru saja pindah tempat tinggal. Josh yang berjanji membantunya justru hanya duduk santai sambil melihat-lihat rumah baru Katreena. Di sini, tuturan Katreena dikategorikan sebagai flouting maksim kualitas karena pada dasarnya, apa yang ia ucapkan mengandung makna lain yaitu menyindir Josh dengan begitu Katreena berharap Josh mau membantunya membereskan barang-barang yang masih berantakan. Pada contoh di atas, secara garis besar penerjemah menggunakan teknik penerjemahan kesepadanan lazim sehingga keakuratan pesan pada teks sumber mampu dipertahankan pada teks target. Maka, dapat disimpulkan bahwa teknik penerjemahan yang digunakan dapat berpengaruh pada nilai keakuratan terjemahan.

Berdasarkan pemaparan tersebut, maka penelitian ini bertujuan untuk (1) mengidentifikasi jenis strategi penyimpangan maksim kualitas yang digunakan penutur, (2) mendeskripsikan teknik penerjemahan yang digunakan, dan (3) mendeskripsikan dampak penggunaan teknik yang digunakan terhadap kualitas terjemahan dari aspek keakuratan.

Terdapat beberapa penelitian terdahulu terkait flouting maksim seperti pada penelitian milik Putro \& Iragiliati (2010) dan Andersen (2014). Kedua penelitian tersebut sudah mengklasifikasikan jenis flouting maksim prinsip kerjasama namun tidak dikaitkan dengan penerjemahan. Lebih lanjut, penelitian dengan topik serupa dan sudah dikaitkan dengan penerjemahan telah dilakukan oleh Putri (2016), Nugraha (2016) dan Hapsari (2016). Pertama, peneltitian yang fokus pada terjemahan seluruh tuturan yang mengandung pelanggaran maksim prinsip kerjasama (Nugraha, 2016), sedangkan penelitian kedua, fokus hanya pada turn dari terjemahan tuturan yang mengandung pelanggaran maksim (Putri, 2016), dan penelitian selanjutnya mengkhususkan pada terjemahan tuturan direktif menjawab saja (Hapsari, 2016). Dari penelitian-penelitian tersebut, tuturan yang dimaksud kemudian dianalisis teknik penerjemahannya serta dianalisis kualitas terjrmahannya. Sementara itu, penelitian ini tidak memfokuskan analisis pada jenis tuturan tertentu akan tetapi pada seluruh tuturan yang 
mengakomodasi penyimpangan maksim kualitas pada novel Me Before You. Selanjutnya pada penelitian ini, terjemahan dianalisis teknik penerjemahannya dan dinilai kualitas terjemahannya dari aspek keakuratan.

\section{TEORI DAN METODOLOGI}

Agar sebuah percakapan berlangsung secara efisien dan efektif, setiap pelaku tutur hendaknya memperhatikan prinsip-prinsip yang berlaku dalam komunikasi (Wijana \& Muhammad, 2011). Namun, tak jarang pelaku tutur melakukan pelanggaran. Salah satu bentuk pelanggaran yang dimaksud disebut dengan penyimpangan (flouting) maksim prinsip kerjasama. Penyimpangan maksim adalah sebuah cara tertentu yang secara jelas dilakukan penutur berharap mitra tuturnya menangkap dan menyimpulkan sendiri maksud tersembunyi dari ujaran yang diujarkan oleh penutur (Grundy, 2000). Penyimpangan maksim kualitas terjadi jika penutur mengatakan sesuatu yang tidak sesuai dengan kenyataan yang ada atau tidak sesuai dengan apa yang ada di dalam pikiran penutur (Cutting, 2002). Dalam melakukan penyimpangan maksim kualitas, penutur dapat menerapkan pertanyaan retoris (rhetorical questions), maupun penggunaan gaya teks (figure of speech) seperti ironi, sarkasme, metafora, hiperbola dan lain sebagainya sebagai strategi (Brown \& Levinson,1987; Cutting, 2002; Birner, 2013).

Teknik penerjemahan merupakan cara mengalihkan pesan teks dari bahasa sumber ke teks bahasa sasaran yang digunakan pada tataran mikro seperti kata, frasa, klausa, kalimat yang bisa dilihat dengan membandingkan kedua teks. Lebih lanjut, teknik penerjemahan digunakan sebagai alat untuk menganalisis produk terjemahan (Molina and Albir, 2002). Di dalam penelitian ini, teori teknik penerjemahan milik Molina dan Albir (2002) digunakan sebagai acuan dalam menganalisis teknik penerjemahan ujaran yang mengakomodasi penyimpangan maksim kualitas. Terdapat 18 teknik penerjemahan diantaranya adalah adaptasi, amplifikasi, peminjaman, kalke, kompensasi, deskripsi, kreasi diskursif, kesepadan lazim, generalisasi, amplifikasi linguistik, kompresi linguistik, harfiah, modulasi, partikulasi, reduksi, substitusi, transposisi dan variasi. Alasan peneliti menggunakan teori tersebut dikarenakan teknik penerjemahan ini cukup lengkap, jelas dan memudahkan peneliti untuk mengklasifikasikan setiap data yang diteliti.

Machali (2000) berpendapat bahwa penilaian kualitas terjemahan penting ditujukan untuk: (1) menciptakan hubungan dialektik antara teori dan praktik, dan (2) kepentingan kriteria dan standar dalam menilai kompetensi penerjemah. Oleh karena itu, ada beberapa kriteria yang harus diperhatikan seperti ketepatan padanan pada aspek semantik, linguistik, dan pragmatik. Hal tersebut sejalan dengan pendapat (Akhiroh, 2013) yang juga menyatakan bahwa terjemahan dikatakan berkualitas jika memenuhi standar dan kriteria tertentu. Terdapat tiga kriteria sebagai acuan dalam menilai kualitas suatu terjemahan yaitu keakuratan, keberterimaan dan keterbacaan (Nababan dkk, 2012). Dalam penelitian ini, kualitas terjemahan hanya difokuskan pada penilaian aspek keakuratan saja. Secara umum, keakuratan berkaitan dengan makna. Keakuratan merupakan sebuah istilah yang digunakan dalam pengevaluasian terjemaha untuk merujuk pada apakah teks bahasa sumber dan teks bahasa sasaran sudah sepadan ataukah belum. Konsep kesepadanan mengarah pada kesamaan isi atau pesan antar keduanya. Sedangkan keberterimaan berkaitan dengan kaidah bahasa dan norma budaya (ibid).

Penelitian ini termasuk dalam jenis penelitian kualitatif yang bersifat deskriptif. Lokasi yang ditetapkan dalam penelitian ini adalah novel Me Before You karya Jojo Moyes dan terjemahannya. Setting dalam penelitian ini adalah Stortford, Inggris. Partisipan yang terlibat dalam penelitian ini ialah semua tokoh pada novel tersebut. Sedangkan peristiwanya sendiri adalah berupa ujaran yang mengakomodasi penyimpangan maksim 
kualitas yang ada di dalam novel teks sumber (inggris) serta dalam teks terjemahan (Indonesia). Sumber data dalam penelitian ini adalah novel Me Before You karya Jojo Moyes diterbitkan pada 5 Januari 2012 dan novel terjemahannya "Sebelum Mengenalmu", diterjemahkan oleh Tanti Lesmana dan diterbitkan oleh PT Gramedia Pustaka Utama pada 3 Juni 2016. Data diperoleh dengan menggunakan 2 metode yaitu analisis dokumen dengan menggunakan teknik simak catat, dan focus group discussion dengan menggunakan kuesioner. Sementara itu analisis data dilakukan dengan mengacu pada teori (Spradley, 1997), yaitu melalui empat tahapan besar: analisis domain, analisis taksonomi, analisis komponensial dan analisis tema budaya. Penilaian kualitas terjemahan dalam penelitian ini mengacu pada instrumen penilaian milik Nababan, dkk (2012). Berikut ini akan dipaparkan tabel instrumen penilaian tingkat keakuratan terjemahan.

Tabel 1. Instrumen Penilaian Keakuratan Terjemahan (Nababan dkk, 2012)

\begin{tabular}{lcl}
\hline Kategori terjemahan & Skor & Parameter kualitatif \\
\hline Akurat & 3 & $\begin{array}{l}\text { Makna kata, istilah, frasa, klausa atau kalimat dalam bahasa } \\
\text { sumber dialihkan secara akurat dalam bahasa sasaran, sama } \\
\text { sekali tidak ada distorsi }\end{array}$ \\
\hline Kurang akurat & $\begin{array}{l}\text { Sebagian besar makna, istilah teknis, frasa, klausa atau kalimat } \\
\text { dalam bahasa sumber dialihkan secara akurat ke dalam bahasa } \\
\text { sasaran. Namun masih ada distorsi makna atau terjemahan } \\
\text { makna ganda (taksa) ataupun reduksi yang mengganggu } \\
\text { keutuhan pesan. }\end{array}$ \\
\hline Tidak akurat & $\begin{array}{l}\text { Makna kata, istilah teknis, frasa, klausa atau kalimat bahasa } \\
\text { sumber dialihkan secara tidak akurat dalam bahasa sasaran atau } \\
\text { dihilangkan. }\end{array}$ \\
\hline
\end{tabular}

\section{TEMUAN DAN PEMBAHASAN}

\section{A. Temuan}

\section{Strategi penyimpangan maksim kualitas}

Hasil analisis menunjukkaan terdapat sebanyak 139 ujaran yang mengakomodasi penyimpangan maksim kualitas. Dalam menganalisis jenis strategi yang diterapkan pelaku tutur penelitian ini mendasarkan analisisnya pada teori milik Brown \& Levinson (1987), Cutting (2002), Birner (2013). Berdasar teori tersebut, diketahui terdapat 7 jenis strategi penyimpangan maksim kualitas. Distribusi data terkait jenis strategi penyimpangan maksim kualitas secara lebih rinci disajikan dalam tabel berikut:

Tabel 2. Klasifikasi Strategi Flouting Maksim Kualitas

\begin{tabular}{clcc}
\hline No & Strategi & Jumlah & Persentase \\
\hline 1 & Sarkasme & 46 & $33,09 \%$ \\
\hline 2 & Ironi & 40 & $28,78 \%$ \\
\hline 3 & Falsehood & 24 & $17,26 \%$ \\
\hline 4 & Hiperbola & 12 & $8,63 \%$ \\
\hline
\end{tabular}




\begin{tabular}{clcc}
\hline 5 & Rhetorical question & 10 & $7,2 \%$ \\
\hline 6 & Simile & 5 & $3,6 \%$ \\
\hline 7 & Metafora & 2 & $1,44 \%$ \\
\hline & Total & $\mathbf{1 3 9}$ & $\mathbf{1 0 0 \%}$ \\
\hline
\end{tabular}

\section{Teknik Penerjemahan yang digunakan dalam menerjemahkan tuturan yang mengakomodasi flouting maksim kualitas}

Acuan teknik penerjemahan yang digunakan pada penelitian ini adalah milik Molina \& Albir (2002) yang terdiri dari 18 teknik. Namun demikian, temuan teknik penerjemahaan yang diaplikasikan dalam menerjemahkan tuturan yang mengakomodasi flouting maksim kualitas pada novel ini hanya ditemukan 14 teknik saja. Persentase teknik penerjemahan dapat dilihat seperti pada tabel 3 berikut ini:

Tabel 3. Klasifikasi Teknik Penerjemahan yang igunakan dalam Menerjemahkan Tuturan yang Mengakomodasi Flouting Maksim Kualitas

\begin{tabular}{|c|c|c|c|}
\hline No. & $\begin{array}{c}\text { Kemunculan teknik } \\
\text { penerjemahan }\end{array}$ & Jumlah & Persentase \\
\hline 1. & Kesepadanan Lazim & 454 & $62,62 \%$ \\
\hline 2. & Amplifikasi (Eksplisitasi) & 80 & $11,04 \%$ \\
\hline 3. & Modulasi & 69 & $9,52 \%$ \\
\hline 4. & Peminjaman Murni & 29 & $4 \%$ \\
\hline 5. & Implisitasi & 24 & $3.31 \%$ \\
\hline 6. & Transposisi & 17 & $2,34 \%$ \\
\hline 7. & Amplifikasi (Adisi) & 11 & $1.52 \%$ \\
\hline 8. & Reduksi & 11 & $1,52 \%$ \\
\hline 9. & Generalisasi & 7 & $0,96 \%$ \\
\hline 10. & Harfiah (Literal) & 7 & $0,96 \%$ \\
\hline 11. & Variasi & 6 & $0,83 \%$ \\
\hline 12. & Kreasi Diskursif & 4 & $0,55 \%$ \\
\hline 13. & Partikularisasi & 4 & $0,55 \%$ \\
\hline 14. & Deskripsi & 2 & $0,28 \%$ \\
\hline & Total & 725 & $100 \%$ \\
\hline
\end{tabular}

\section{Tingkat keakuratan terjemahan tuturan yang mengakomodasi flouting maksim kualitas}

Kualitas keakuratan terjemahan tuturan yang mengakomodasi penyimpangan maksim kualitas yang ditemukan pada penelitian ini meliputi 3 kategori yaitu terjemahan yang akurat, kurang akurat dan tidak akurat. Persentase temuan yang berkaitan dengan keakuratan terjemahan disajikan dalam tabel 4 berikut ini: 
Tabel 4. Persentase Tingkat Keakuratan Terjemahan

\begin{tabular}{llll}
\hline No & Kualitas & Frekuensi & Persentase \\
\hline 1. & Akurat & 116 & $83,45 \%$ \\
\hline 2. & Kurang akurat & 21 & $15,11 \%$ \\
\hline 3. & Tidak akurat & 2 & $1,44 \%$
\end{tabular}

Tabel di atas menunjukkan bahwa data terjemahan akurat memiliki persentase yang cukup tinggi yaitu sebesar $83,45 \%$, sedangkan untuk data terjemahan kurang akurat sebesar 15,11\%, dan untuk data tidak akurat hanya sebesar 1,44\%. Berikut ini akan dijelaskan mengenai masing-masing kategori beserta contoh data.

\section{Akurat}

Frekuensi kemunculan data yang tergolong akurat dalam penelitian ini adalah sebesar $83,45 \%$. Berikut adalah beberapa contoh data terjemahan akurat:

\section{Contoh 1}

138/C25/BSu222/BSa562

\section{Bahasa sumber}

$\begin{array}{lll}\text { Nathan } & : & \text { He is in a good mood. } \\ \text { Lou } & : & \text { Is he? } \\ \text { Nathan } & : & \text { He says you're trying to poison him. } \\ \text { Lou } & : & \text { Yes... well... give me time. }\end{array}$

\section{Bahasa sasaran}

$\begin{array}{lll}\text { Nathan } & : & \text { Suasana hatinya sedang bagus. } \\ \text { Lou } & : & \text { Oya? } \\ \text { Nathan } & : & \text { Dia bilang kau mencoba meracuninya. } \\ \text { Lou } & : & \text { Yah... well... memang perlu waktu. }\end{array}$

Contoh 2

055/C11/BSu104/BSa243

Bahasa Sumber

Will : Don't worry, it's only cashmere.

\section{Bahasa sasaran}

\section{Will : Tidak apa-apa, toh bahannya Cuma kasmir kok.}

Contoh 1 dan 2 merupakan data terjemahan yang akurat karena makna pada teks sumber ditransfer ke dalam teks sasaran dengan tepat. Tidak terdapat distorsi makna dan seluruh informasi dan pesan pada teks sumber berhasil diterjemahkan dengan sempurna ke dalam teks sasaran. Jika dilihat dari teknik penerjemahannya, penerjemah menggunakan teknik kesepadanan lazim

\section{Kurang akurat}

Frekuensi kemunculan data terjemahan yang tergolong pada kategori kurang akurat adalah sebesar $15,11 \%$.

Contoh 3

063/C11/BSu109/BSa256 


\author{
Bahasa sumber \\ A customer : Didn't he like it? \\ Lou : I don't know. Perhaps he would have liked it better if it hadn't \\ come with a side order of rubberneck.
}

\title{
Bahasa sasaran
}

Pelanggan : Dia tidak suka rotinya?

Lou : Entah ya. Mungkin dia akan lebih menikmatinya kalau tidak kalian pandangi terus-terusan dengan tampang blo'on.

Contoh 4

034/C6/BSu65/BSa146

Bahasa sumber

Will : Bumblebee tight? Black and yellow stripes?

Georgeous.

Lou : That's a bit harsh.

\section{Bahasa sasaran}

Will : Celana kaus bumblebee? Garis-garis hitam-dan-kuning?

\section{Hebat.}

Lou : Komentarmu agak keterlaluan.

Contoh 3 dan 4 dikategorikan sebagai terjemahan kurang akurat karena terdapat distorsi makna antara teks sumber dan teks target. Jika diperhatikan dari konteks situasinya, frasa $a$ side of rubberneck pada contoh 3 mengandung arti "sangat ingin tahu" atau "penasaran", namun kemudian diterjemahkan menjadi "tampang blo'on" sehingga dinilai kurang sepadan. Sementara itu kata gorgeous yang dimaksudkan untuk menyindir selera pakaian Lou, namun pada teks target kata tersebut diterjemahkan menjadi "hebat" dan makna berubah menjadi menyindir sifat Lou secara keseluruhan. Tidak sepadannya makna pada kedua teks menyebabkan nilai keakuratan terjemahan rendah (2) dan dikategorikan kurang akurat.

\section{Tidak akurat}

Berdasarkan temuan, frekuensi kemunculan terjemahan yang tidak akurat hanya sebesar 1,44\%. Berikut ini salah satu contoh terjemahan yang tidak akurat:

Contoh 5

064/C11/BSu109/BSa257

\section{Bahasa sumber}

Nathan : I think we're going to need some help. I can't even get the chair back on the path.

Will $\quad$ : I am not ending today with a fireman's lift.

\section{Bahasa sasaran}

Nathan : Kurasa kita butuh sedikit bantuan. Aku bahkan tidak bisa mendorong kursi ini ke jalan setapak lagi.

Will : : Aku tidak mau digendong ke mobil.

Contoh 5 dikatakan sebagai terjemahan yang tidak akurat karena kalimat pada teks sumber diterjemahkan berbeda dari apa yang dimaksudkan pada teks sumber. Istilah fireman's lift digunakan sebagai gambaran gendong ala petugas damkar (menggendong 
dengan meletakkan badan seseorang dipundak petugas damkar). Disini tokoh Will menggunakan gambaran tersebut untuk menegaskan maksudnya pada Nathan, yaitu ia tidak ingin bantuan dari siapapun. Sebaliknya, penerjemah menggunakan teknik kreasi diskursif untuk menerjemahkan istilah tersebut, sehingga terjemahan menjadi sangat berbeda dengan teks sumber. Hal ini menyebabkan terjemahan menjadi tidak akurat.

\section{B. Pembahasan}

Setelah melalui proses pengklasifikasian jenis strategi yang diterapkan dalam melakukan flouting maksim kualitas, diketahui bahwa sarkasme dan ironi menjadi strategi yang paling dominan. Dari hasil temuan, diketahui bahwa penerapan sarkasme dan ironi lebih banyak digunakan oleh Will dan Lou sebagai tokoh utama. Hal ini sesuai dengan watak dan karakter masing-masing pada cerita dalam novel. Penulis memunculkan kesan yang kuat terhadap karakter kedua tokoh melalui pernyataan-pernyataan yang mengandung flouting maksim dengan sarkasme dan ironi untuk menunjukkan perasaan negatif terhadap mitra tutur. Penjelasan tersebut sesuai dengan hasil penelitian Andersen (2014). Ia mengatakan bahwa kepribadian tiap-tiap tokoh tercermin dari jenis flouting maksim yang ia gunakan. Berikutnya, hiperbola merupakan jenis strategi ketiga yang mendominasi. Lagi-lagi penggunaan hiperbola sebagai strategi dalam melakukan flouting maksim kualitas PK kebanyakan diterapkan oleh Will sebagai tokoh utama dan Nathan sebagai tokoh pendukung. Hal ini dilatarbelakangi oleh karakter Will yang digambarkan sebagai seorang pria yang sombong, dingin dan ketus namun memiliki hati yang baik dan suka bercanda dengan Nathan, perawatnya. Will dan Nathan sering menggunakan tuturantuturan yang mengandung hiperbola untuk berkelakar satu sama lain atau sekedar bercanda untuk mencairkan suasana. Hal ini sejalan dengan apa yang diungkapkan oleh Cutting (2002) bahwa hiperbola sering digunakan sebagai permulaan humor. Strategi keempat adalah falsehood. Penggunaan strategi ini sering ditemui sebagaimana salah satu ciri tuturan yang mengandung flouting maksim adalah dengan menyatakan sesuatu yang berlawanan dengan kenyataan atau dapat dikatakan pelaku tutur berbohong karena tidak mengungkapkan sesuatu apa adanya sesuai situasi dan kondisi yang ada. Hal ini sesuai dengan teori milik Birner (2013) yang menyatakan bahwa pernyataan bohong merupakan akibat dari pelanggaran maksim kualitas. Strategi kelima adalah rhetorical question. Rhetorical question dalam penelitian ini lebih banyak bertujuan untuk sekedar menekankan maksud yang ingin diungkapkan penutur secara tidak langsung. Hal ini sejalan dengan apa yang dikemukakan Karifka (1995) dan Banuazizi \& Creswell (1999) yang menyebutkan bahwa rhetorical question digambarkan sebagai pemilihan dan penegasan satu jawaban, baik positif atau negatif dari pertanyaan atau pernyataan nonretoris sebelumnya. Berikutnya, strategi dengan jumlah kecil adalah simile dan metafora. Dengan ditemukannya sedikit data dengan simile dan metafora sebagai strategi yang diterapkan dalam melakukan flouting maksim kualitas maka peneliti beranggapan bahwa hal tersebut dilatarbelakangi oleh jenis dokumen yang digunakan sebagai lokasi penelitian. Dalam penelitiannya, Putro \& Iragiliati (2010) menggunakan iklan susu bayi sebagai lokasi penelitian. Hasil penelitian tersebut mengungkap bahwa metafora justru menjadi strategi flouting maksim kualitas yang paling banyak digunakan.

Berdasar hasil temuan, teknik kesepadanan lazim merupakan teknik yang paling mendominasi. Teknik ini digunakan untuk mencari padanan lazim dan sepadanan dalam BSa. Penggunaan teknik kesepadanan lazim tidak lepas dari konteks situasi yang membangun percakapan. Hal ini sejalan dengan flouting maksim itu sendiri yang samasama tidak bisa lepas dari konteks situasinya. Dengan tingginya frekuensi digunakannya teknik ini, maka makna implisit yang terkandung dalam tuturan terjaga. Penggunaan teknik ini kemudian dikatakan memberi berdampak positif pada terjemahan tuturan yang 
mengakomodasi flouting maksim kualitas PK dalam novel Me Before You karya Jojo Moyes. Selanjutnya, diikuti oleh teknik amplifikasi (eksplisitasi). Meskipun teknik ini digunakan untuk mengeksplisitkan pesan yang ada dalam bahasa sumber, namun pesan dan makna keseluruhan dari flouting maksim kualitas PK tetap terjaga pada bahasa sasaran. Hal ini kemudian menunjukkan bahwa dengan terjaganya pesan implisit tersebut maka pergeseran strategi flouting maksim kualitas juga tidak akan berubah. Berikutnya adalah teknik peminjaman murni. Teknik ini digunakan untuk menerjemahkan nama tokoh, benda dan tempat. Teknik penerjemahan lainnya seperti transposisi dan implisitasi diketahui hanya mempengaruhi struktur permukaan kalimat dan sebagian makna serta tidak berpengaruh pada pergeseran strategi flouting maksim kualitas. Sementara teknik penerjemahan generalisasi, partikularisasi dan juga deskripsi digunakan dengan tujuan agar pembaca dapat memahami maksud terjemahan tuturan yang mengakomodasi flouting maksim kualitas PK dengan baik. Selanjutnya, Teknik variasi dalam penelitian ini diketahui tidak berpengaruh negatif pada penilaian kualitas terjemahan. Bererbeda halnya dengan teknik Amplifikasi (adisi) dan modulasi pada penelitian. Penggunaan teknik adisi memberikan dampak positif dan juga negatif pada kualitas terjemahan. Dari sebanyak 11 kali kemunculan teknik ini, 8 diantaranya berdampak positif dengan memberi informasi lebih pada bahasa saran sehingga mempermudah pembaca dalam memahami pesan dalam teks. Sedangkan 3 diantara kemunculannya berdampak negatif dan mengakibatkan terjemahan menjadi kurang akurat akibat pesan tidak tersampaikan dengan baik menjadikan terjemahan antara bahasa sumber dan bahasa sasaran tidak sepadan. Di lain sisi, penggunaan sebagian kecil teknik modulasi mempengaruhi keakuratan terjemahan karena adanya perubahan sudut pandang yang berpengaruh pada makna pesan yang terkandung. Setidaknya 2 kali kemunculan teknik ini menyebabkan terjemahan dikategorikan sebagai kurang akurat. Lebih lanjut, teknik reduksi, harfiah (literal) dan kreasi diskursif diketahui memberi dampak buruk pada penilaian kualitas terjemahan. Kemunculan teknik reduksi dalam penelitian ini digunakan untuk menghilangkan sebagian informasi pada bahasa sumber, sedangkan penggunaan teknik harfiah pada penelitian ini membuat terjemahan lepas konteks dari segi apapun sehingga terjemahan diterjemahkan apa adanya.

Terjemahan yang akurat dipengaruhi oleh kesepadanan makna antara BSu dan BSa sehingga kurang akuratnya terjemahan tuturan disebabkan oleh sebagian pesan yang tidak disampaikan dengan baik dalam BSa mengakibatkan pembaca tidak mendapatkan pesan atau informasi secara utuh, sedangkan ketidakakuratan terjemahan dipengaruhi oleh perbedaan makna antara BSu dan BSa. Dari 139 data terjemahan yang diteliti, 116 diantaranya akurat, 21 kurang akurat dan 2 tidak akurat. Pemerolehan nilai keakuratan yang tinggi tidak lepas dari pemertahanan pesan yang baik yang dihasilkan oleh teknik kesepadanan lazim. Hasil penelitian ini sejalan dengan penelitian milik Sumardiono (2011) dan Hapsari (2016), dari ketiga hasil penelitian menunjukkan bahwa penerapan teknik kesepadanan lazim pada terjemahan berdampak positif bagi kualitas terjemahan itu sendiri.

Dalam penelitian ini, penulis menemukan tiga komponen hasil analisis yang memiliki keterkaitan satu sama lain. Hubungan ketiga komponen tersebut secara sederhana dapat dideskripsikan bahwa teknik penerjemahan yang digunakan dapat menentukan apakah bentuk strategi flouting maksim kualitas pada bahasa sumber mengalami pergeseran atau tidak dalam bahasa sasaran. Dengan kata lain, jika strategi mengalami pergeseran, maka akan berpengaruh pada nilai keakuratan terjemahan. Pengaruh penggunaan teknik penerjemahan terhadap pergeseran strategi flouting maksim dapat dilihat pada tabel 5 berikut ini: 
Tabel 5. Pengaruh teknik penerjemahan terhadap pergeseran strategi flouting maksim kualitas

\begin{tabular}{|c|c|c|c|c|c|c|c|c|c|c|c|c|c|c|c|c|}
\hline \multirow[t]{2}{*}{ No } & \multirow{3}{*}{$\begin{array}{c}\text { Bentuk pergeseran strategi flouting } \\
\text { maksim kualitas PK }\end{array}$} & \multicolumn{12}{|c|}{ Teknik penerjemahan } & \multicolumn{3}{|c|}{$\begin{array}{l}\text { Keakuratan } \\
\text { Terjemahan }\end{array}$} \\
\hline & & \multirow{2}{*}{$\overline{0}$} & 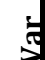 & $\frac{\pi}{T}$ & 可 & 웡 & $\sum$ & 吾 & $=$ & d & 氙 & : & $\theta$ & & & \\
\hline & & & & & & & & & & & & & & & & \\
\hline 1. & Sarkasme $\rightarrow$ statement & 5 & - & - & - & - & 1 & - & 1 & - & - & - & - & - & $\checkmark$ & - \\
\hline 2. & Ironi $\rightarrow$ ironi (downgrading) & 3 & - & - & - & - & - & - & - & - & - & 1 & - & - & $\checkmark$ & - \\
\hline 3. & Ironi $\rightarrow$ ironi (upgrading) & 1 & - & - & - & - & - & - & - & - & - & 1 & - & - & $\checkmark$ & - \\
\hline 4. & Hiperbola $\rightarrow$ hiperbola (downgrading) & 5 & - & - & - & 1 & - & - & - & - & - & - & 1 & - & $\checkmark$ & - \\
\hline 5. & Hiperbola $\rightarrow$ statement & - & - & - & - & - & - & - & - & - & - & - & 1 & - & - & $\checkmark$ \\
\hline 6. & Simile $\rightarrow$ simile (downgrading) & 2 & 1 & - & 1 & 3 & - & - & - & 1 & - & - & 1 & - & $\checkmark$ & - \\
\hline 7. & Metafora $\rightarrow$ metafora (downgrading) & 8 & - & 1 & - & - & - & 1 & - & - & 1 & - & - & - & $\checkmark$ & - \\
\hline
\end{tabular}

Keterangan:

PL (Kesepadanan Lazim), Var (Variasi), Eks (Amplifikasi: Eksplisitasi), Mod (Modulasi), Imp (Implisitasi), Lit (Literal), Tra (Transposisi), Red (Reduksi), Adi (Eksplisitasi: Adisi), KD (Kreasi Diskursif).

\section{SIMPULAN}

Dari pembahasan yang telah dipaparkan dalam paragraf sebelumnya, maka dapat disimpulkan bahwa terdapat sebanyak 139 tuturan yang mengakomodasi flouting maksim kualitas yang ditemukan pada novel Me Before You dengan 7 jenis strategi dan 14 teknik penerjemahan. Dari 139 data yang telah dianalisis, dapat dikatakan bahwa nilai keakuratan terjemahan tuturan yang mengakomodasi flouting maksim kualitas dalam novel Me Before You secara keseluruhan cenderung baik. Namun demikian diketahui bahwa beberapa data mengalami pergeseran strategi yang dipengaruhi oleh penggunaan teknik tertentu. Diantara teknik penerjemahan yang berpengaruh adalah modulasi, generalisasi, literal, reduksi, amplifikasi (adisi) dan kreasi diskursif. Teknik - teknik tersebut kemudian diketahui berpengaruh pada rendahnya nilai keakuratan terjemahan.

Dari kesimpulan tersebut maka penulis ingin menyampaikan saran bahwa penerjemah hendaknya mampu memilih dan menerapkan teknik penerjemahan yang mengutamakan keakuratan dan keutuhan pesan bahasa sumber agar pesan dapat tersampaikan dengan baik oleh pembaca bahasa sasaran dikarenakan tidak semua pembaca memiliki latar belakang, budaya dan keilmuan yang sama. Penggunaan teknik yang tidak tepat mungkin saja terjadi karena penerjemah kurang memahami pesan atau makna dari sebuah tuturan tertentu. Oleh karena itu, untuk menerjemahkan tuturan yang mengakomodasi flouting maksim kualitas (implikatur), penerjemah seharusnya menghindari penggunaan beberapa teknik tertentu, terutama teknik literal, reduksi, amplifikasi (adisi) dan kreasi diskursif. Teknik-teknik tersebut dinilai dapat memberi efek negatif pada keakuratan terjemahan. 


\section{DAFTAR PUSTAKA}

Akhiroh, N. S. (2013). The influence of translation technique on the quality of the translation of international news in Seputar Indonesia daily. Language Circle Journal of Language and Literature, Vol. 7, No. 2, 41-51.

Andersen, N. (2013). Flouting the maxims in comedy: an analysis of flouting in the comedy series community. (Master's thesis). Karlstads University.

Banuazizi, A., \& Creswell, C. (1999). 'Is that a real question? Final rises, final falls and discourse function in yes-no question intonation'. CLS 35, 1-14.

Birner, B. J. (2013). Introduction to pragmatics. UK: Wiley-Blackwell.

Brown, P., \& Stephen, L. (1987). Politeness: some universals in language usage. Cambridge: Basil blackwell.

Cutting, J. (2002). Pragmatics and discourse: A resource for students. New York: Routledge.

Grice, H. P. (1975). Logic and conversation. New York: Oxford University Press.

Grundy, P. (2000). Doing pragmatics. London: Oxford University Press Inc.

Karifka, M. (1995). The semantics and pragmatics of polarity items. Linguistic Analysis, 25, 149.

Larson, M. L. (1984). Meaning-based translation: A guide to cross-language equivalence. New York: University Press of America.

Machali, R. (2000). Pedoman bagi penerjemah. Jakarta: Gramedia Widiasarana Indonesia.

Molina, L., \& Albir, A. (2002). 'Translation techniques revisited: A dynamic and functionalist approach'. Meta: Translators' journal, Vol. 47, No. 4, 499-512.

Moyes, J. (2012). Me before you, [PDF]. https: // bookwormbyheart. blogspot. co. id/ 2016/ 03/ jojo- moyes -book -collection -kindle- epub. html, diakses tanggal 17 November 2016.

Moyes, J. (2016). Me Before You. (Lesmana, T, Sebelum mengenalmu). Jakarta: PT Gramedia Pustaka Utama.

Nababan, M. R., Nuraeni, A., \& Sumardiono. (2012). 'Pengembangan model penilaian kualitas terjemahan'. Kajian linguistik dan sastra, Vol. 24, no. 1, Juni 2012; 39-57.

Putri, R. (2016). Terjemahan turn yang mengakomodasi flouting maksim prinsip kerjasama dalam novel The Cairo Affair karya Olen Steinhauer. (Tesis). Universitas Sebelas Maret: Surakarta.

Putro, S. C. D., \& Iragiliati, E. (2013). Flouting the maxim in baby milk slogans shown on TV advertisements. (Tesis). State University of Malang.

Spradley, J. P. (1997). Metode etnografi. Yogyakarta: Tiara Wacana Yogya.

Sumardiono. (2011). Kajian terjemahan ujaran yang mengandung implikatur pada novel The Da Vinci Code (Sebuah tinjauan pragmatik pada penerjemahan). (Tesis). Universitas Sebelas Maret: Surakarta. 